\title{
El concepto de libertad en Hannah Arendt
}

para el ejercicio de los derechos humanos* / The concept of freedom according to Hannah Arendt in the application of human rights

* Recibido: 18 de enero de 2016. Aceptado: 26 de febrero de 2016.

Tla-Melaua, revista de Ciencias Sociales. Facultad de Derecho y Ciencias Sociales. Benemérita Universidad Autónoma de Puebla, México / Isss: 1870-6916 / Nueva Época, año 10, núm. 41, octubre 2016/marzo 2017, pp. 6-25. 
El concepto de libertad en la obra de Hannah Arendt constituye un elemento fundamental para actualizar la reflexión y el ejercicio de los derechos humanos en el contexto presente. Su propuesta radica en colocar la acción política en el centro de la libertad para pensar el vínculo entre la ley y su puesta en marcha para realizar los derechos humanos. Con este propósito, argumenta sobre los límites que entraña el principio de que los derechos humanos tienen su concreción en el marco de un sistema estatal soberano, ratificado en todas las declaraciones universales desde la Revolución francesa. Al mismo tiempo, postula la concepción del "derecho a tener derechos" como una alternativa que pone en relación el derecho moral a "ser miembro", con el derecho político de "actuar en la pluralidad y emitir juicios" al interior de una comunidad política.

\section{PALABRAS CLAVE}

Libertad, derechos humanos, soberanía estatal.
The concept of freedom in the work of Hannah Arendt is a fundamental element to update reflection and the application of human rights in the present context. The proposal is to place political action as the center of freedom in order to come up with a link between the law and its implementation to have human rights. With this in mind, it is stated that the limits in principle of human rights are tangible in the framework of a sovereign state system, ratified in all universal declarations since the French Revolution. At the same time, it proposes the concept of the "right to have rights" as an alternative that links the moral right to "membership", with the political right to "act in plurality in order to make judgments" within a political community.

KEYWORDS

Freedom, Human Rights, State Sovereignty.

\footnotetext{
* Profesora investigadora en la Universidad Autónoma de la Ciudad de México. (concepcion.delgado@uacm.edu.mx)
} 
1. Personas "sin Estado": seres sin derechos humanos / 2. El "derecho a tener derechos": un intersticio para escapar al dilema de los derechos humanos / 3. La libertad de acción política y la realización de los derechos humanos

\section{PERSONAS "SIN ESTADO": SERES SIN DERECHOS humanos}

Después de Kant, será Arendt quien continúe el debate sobre las perplejidades que entraña la instrumentación de una concepción de derechos humanos basada en la membrecía política en el marco de un sistema estatal soberano. ${ }^{1}$ En Los origenes del totalitarismo ${ }^{2}$ muestra que la experiencia del siglo xx constituye una crisis para los derechos humanos debido al colapso del sistema del Estado-nación en Europa, materializado en el trayecto de las dos guerras mundiales. El desprecio del totalitarismo por la vida humana y el eventual tratamiento de los seres humanos como entidades "superfluas", que arrojó a millones de personas y pueblos a la condición de "personas sin Estado", mostró que todo el que deja de contar como ciudadano en su país no sólo pierde sus derechos civiles, sino también sus derechos humanos.

En el diagnóstico crítico desarrollado en Los orígenes..., Arendt aborda las causas que llevaron a la crisis y decadencia del Estado-nación moderno, cuyas consecuencias derivaron en el experimento más destructivo de la condición política del hombre: el fenómeno totalitario. En este proceso muestra la incompatibilidad creada por el imperialismo del siglo XIX entre poder político y enriquecimiento económico, dirigida a legitimar las necesidades de una clase burguesa en ascenso. Mediante esta práctica se puso en marcha un imperialismo que olvidó el principio que ordena a los hombres volver la tierra un lugar habitable, introduciendo en ella un sistema de mediaciones legales que sirvieran para proteger la vida de las personas.

Arendt asume una posición extremadamente dura con el pensamiento político moderno, particularmente cuando afirma que sin Hobbes el Estado moderno europeo no habría contado con las bases suficientes para emprender la aventura imperialista: "Las políticas imperialistas, más que cualquier otro factor, han sido las responsables de la decadencia de Europa, haciendo en realidad las profecías de los políticos e historiadores". ${ }^{3}$ Antes de la era imperial

\footnotetext{
${ }^{1}$ Gündogdu, Ayten, "Perplexities of the Rights of Man': Arendt on the Aporias of Human Rights", European Fournal of Political Theory, vol. 11, núm. 1, 2011, pp. 4-24.

${ }^{2}$ Arendt, Hannah, The Origins of Totalitarianism, Nueva York, Harcourt, 1968, pp. 290-302.

${ }^{3}$ Ibidem, p. xix.
} 
no existía nada como una política mundial, y sin ella carecía de sentido la reivindicación totalitaria de dominación global. Durante este período, afirmará Arendt, el sistema de Estado-nación será incapaz de concebir nuevas normas para conducir los asuntos políticos, dejando al garete una masa de apátridas sin cobijo político ni legal.

El dilema que marcará esta época será la "superfluidad" de un gran número de personas devenidas en "masa", de las que la vida económica y política podía prescindir. Esta naturaleza fue producida, en parte, por el proceso de acumulación de capital, resultado de las continuas expropiaciones, de los cambios e invasiones demográficas y del propio desempleo. Pero fue creada también por la concentración de poder dentro de las estructuras burocráticas y del ascenso de un "Estado empleador de administradores de la violencia", cada vez más alejados del ciudadano común y de las instituciones representativas, y más próximos al funcionamiento de una política imperial exterior. En este contexto, la corrosión de las bases del Estado-nación se produce al reducirlo a la mera cobertura administrativa de una extensión colonialista del poder interpretado en términos meramente económicos.

Durante los treinta años en que persistió el imperialismo, iniciado con la Conferencia de Berlín, donde se formalizó la denominada "Lucha por África" (Scramble for Africa), así como las incursiones de las potencias coloniales europeas por parte de Asia y el Pacífico (1884) y, concluido el estallido de la Primera Guerra Mundial (1914), se gestaron las condiciones ideológicas y tecnológicas que acompañarían el fenómeno totalitario del siglo xx y el anuncio de las catástrofes por venir. ${ }^{4}$ La toma del poder por la burguesía y la desestabilización del sistema de Estados-nación acompañaron esta etapa, durante la cual la idea central giró en torno a la expansión competitiva como el "objetivo permanente y supremo de la política". 5

La burguesía europea, ansiosa de ampliar más allá de ultramar su poder recientemente adquirido - $\mathrm{y}$ sin la extensión del acompañamiento de un cuerpo político - impuso sus propios instrumentos oficiales y de conquista con los que estableció un orden supremo, alejado de instituciones legales y políticas que limitaran su acumulación de poder y la escalada de la violencia. Los anteriores colonialismos tenían motivaciones fundamentalmente políticas; sin embargo, el reciente se sustenta únicamente en el interés económico. En este contexto, un cuerpo político acotado se pone al servicio de un poder ilimitado que termina por fracturar la estructura misma del Estado-nación. La novedad de esta forma de imperialismo radica en que las prácticas que generó, y le dieron sustento, introdujeron principios completamente distintos para el ordenamiento de la política. En primer lugar, la expansión (el

\footnotetext{
${ }^{4}$ Ibidem, p. 123.

${ }^{5}$ Ibidem, p. 125.
} 
colonialismo) fue elevada a un principio político legítimo; en segundo, se extendió la idea de que la política ya no podía ser contenida dentro de las fronteras nacionales, dado que ningún Estado podía permanecer indiferente a los imperativos políticos y económicos mundiales. ${ }^{6}$

Lo sorprendente de la interpretación arendtiana es que identifica un concepto que no es político en absoluto, sino que tiene su origen en la especulación económica, donde la expansión significó la ampliación permanente de la producción industrial y las transacciones económicas propias del siglo xx. Esta nueva definición de la política implicó la transfiguración de las formas de gobierno - los sistemas políticos se estructuraron a partir de este momento sobre el principio de la raza y bajo el dominio de la burocracia - y el uso de la violencia como instrumento de gestión legítima, para controlar y asimilar a los pueblos sometidos. El desarrollo de estas prácticas tejerán la urdimbre entre imperialismo y totalitarismo del "efecto boomerang", cuyas experiencias deshumanizantes y desestabilizadoras, instrumentadas en la periferia, finalmente retornarán para infiltrarse en la política europea del siglo Xx. ${ }^{7}$

Arendt señala que la Primera Guerra Mundial desenmascaró esta fachada del sistema político europeo y puso al descubierto el sufrimiento de un vasto número de personas, para quienes las leyes del mundo que las rodeaba, de pronto habían dejado de aplicarse. Argumenta que la guerra reveló la contradicción entre el Estado-nación y los derechos humanos. En nombre del interés nacional, los líderes de Europa provocaron una catástrofe que rozó los límites del continente. La guerra dejó millones de muertes y desplazados. Mientras tanto, los acuerdos de la posguerra buscaban aliviar los daños.

Los intentos desesperados por resolver el problema, sin tomar en cuenta la causa fundamental vinculada con el principio de la soberanía nacional, sólo demostraron que ninguna paradoja política contemporánea es más irónica que la discrepancia entre los esfuerzos de los bien intencionados idealistas. Estos últimos insistían obstinadamente en considerar como "inalienables" los derechos humanos, de los cuales únicamente gozaban los ciudadanos de la mayoría de los países prósperos y civilizados. A pesar de sus buenas intenciones, los reformadores humanitarios estaban destinados a fracasar si se negaban a cuestionar el principio de soberanía nacional - sostenido sobre la triada de identidad nacional, ciudadanía y Estado - y a soslayar la idea de una autoridad global fundada sobre la responsabilidad humana.

La Primera Guerra Mundial precipitó y prefiguró los crímenes contra la humanidad cometidos por los regímenes totalitarios de la Segunda Guerra Mundial, los cuales mostraron con brutalidad su indiferencia y hostilidad hacia los derechos humanos adscritos a la lógica de la soberanía nacional.

${ }^{6}$ Ibidem, pp. 123-124.

${ }^{7}$ Ibidem, p. 294. 
Asimismo, exhibió el vacío y la ineficacia de los derechos naturales enarbolados por el Estado-nación moderno. El modelo de las políticas totalitarias de la discriminación, expulsión y expatriación tuvo el efecto de confrontar a las naciones del mundo a una paradójica e inevitable cuestión: "Si los derechos humanos realmente existen o no, independientemente de todo estatus político específico derivado solamente del hecho de ser seres humanos".

La actuación que tuvieron las naciones del mundo hizo patente su respuesta a esta cuestión: los expulsados y los expatriados no tienen derechos humanos porque, en efecto, éstos no existen para quienes carecen de ciudadanía. La terrible situación de los refugiados, asilados y desplazados reveló claramente que los "derechos del hombre, supuestamente inalienables, demostraban su inaplicabilidad [...] las personas que aparecieron ya no eran ciudadanas de ningún Estado".

Despojadas de su ciudadanía, las personas "sin Estado" no solamente fueron arrojadas de su hogar sino también de su estatus político; sometidas a la privación fundamental, la pérdida de un lugar en el mundo, donde sus opiniones adquieren significado y sus acciones se concretan; quedan desprovistas de la básica dignidad humana, investida de la posibilidad de actuar como agentes políticos y morales. En este sentido, Arendt insiste en que la dignidad humana requiere de una nueva garantía debido a que la idea kantiana de un mundo cosmopolita, configurado por repúblicas específicas, y respetuoso de los derechos naturales del hombre sobre los que se sostenía, había sido destruida.

Aunque Arendt comparte la sospecha de Kant con respecto a la identificación del Estado social con el civil — propiamente estatal-y su antipatía hacia un supuesto Estado mundial, sostiene que la única forma de que los derechos humanos, a los que se otorga una validez inconmovible desde el siglo XVIII, no se conviertan en letra muerta depende de la institución de una comunidad política heredera de las tareas y objetivos del fracasado Estado-nación. Desde esta perspectiva, la crítica de Arendt al listado contenido, tanto en la Declaración de 1789 como en la de 1948, enfatiza la "pérdida de realidad", toda vez que incluye derechos que no se dirigen a los seres humanos sino únicamente a los miembros de una entidad política organizada. ${ }^{8}$

$\mathrm{El}$ análisis de Arendt visibiliza el perverso proceso de transformación del Estado moderno que gira de un instrumento de derecho a un mecanismo de discrecionalidad sin ley al servicio de la nación: "La nación ha conquistado al Estado, el interés nacional tiene prioridad sobre la ley". ${ }^{9}$ Ciertamente, el peligro de este desarrollo es inherente a la estructura del Estado-nación desde el principio. Con el fin de establecer un Gobierno constitucional, los

\footnotetext{
${ }^{8}$ Arendt, Hannah, "The Rights of Man: What are They?", Modern Reviewe, vol. 3, núm. 1, 1949, pp. 24-36. ${ }^{9}$ Arendt, Hannah The Origins..., op. cit., p. 275.
} 
Estados-nación siempre estuvieron representados y basados en el Estado de derecho y en contra de la arbitrariedad administrativa y despótica. Sin embargo, en el mismo instante en que se rompió el precario equilibrio entre el interés nacional y las instituciones legales, la desintegración de esta forma de gobierno y organización de los pueblos produjo resultados aterradores. Paradójicamente, la desintegración del Estado-nación comenzó precisamente cuando el derecho a la autodeterminación nacional fue reconocido por todos los países europeos y cuando su esencial convicción, la supremacía de la voluntad de la nación sobre todas las instituciones legales y "abstractas", fueron universalmente aceptadas. ${ }^{10}$

En el momento en que los Estados comenzaron a practicar desnaturalizaciones masivas en contra de las minorías no deseadas, los refugiados, personas "sin Estado" y desplazados, se convirtieron en portadores de una categoría especial de seres humanos instrumentada mediante las acciones del Estado-nación, y en un sistema de Estados-nación delimitado por la territorialidad de las comunidades políticas organizadas. Es decir, se convirtieron en un orden internacional basado en la centralidad del Estado, ${ }^{11}$ donde el estatus legal depende de la protección de la más alta autoridad que controla el territorio en el que la persona reside y de quien emite los documentos a los que ésta tiene derecho. Cuando alguien pierde su pertenencia es arrojado al anonimato del ser humano, y queda desasido de todo derecho. ${ }^{12}$

\section{El “DERECHO A TENER DEREChOS”: UN INTERSTICIO PARA ESCAPAR AL DILEMA DE LOS DERECHOS HUMANOS}

En Los origenes del totalistarismo, Arendt revela con aguda claridad la imposibilidad de reconocimiento y realización de los derechos humanos fuera de las estructuras del sistema de Estados-nación, así como su radical consecuencia: la anulación de la libertad de acción.

La primera derrota sufrida con la privación de los derechos fue la pérdida del hogar, lo que significó la total ruptura del tejido social del espacio donde [los seres humanos] habían nacido y construido su lugar en el mundo. Esta calamidad está lejos de todo precedente; a lo largo de la historia, las migraciones forzadas de personas o pueblos enteros, por motivos políticos o económicos, han sido vistas como sucesos cotidianos. Sin embargo, lo que carece de precedente no es

\footnotetext{
${ }^{10}$ Ibidem, p. 275.

${ }^{11}$ Benhabib, Seyla, "Reason-Giving and Rights-Bearing: Constructing the Subject of Rights", Constellations, vol. 20, núm. 1, 2013, pp. 37-50.

${ }_{12}$ Benhabib, Seyla, The Rights of Others. Aliens, Residents and Citizens, Cambridge, Cambridge University Press, 2004, p. 55.
} 
la pérdida del hogar, sino la imposibilidad de encontrar uno nuevo. [...] La segunda pérdida sufrida con la privación de los derechos fue la pérdida de protección del Gobierno. Esto no sólo implicó la pérdida del estatus legal en su propio país, sino también en cualquier otro [...] La calamidad de la pérdida de derechos no es que ellos [los seres humanos] sean privados de la vida, de la libertad, de perseguir la felicidad o exigir la igualdad ante la ley y la libertad de opinión -fórmulas que fueron designadas para resolver problemas dentro de las comunidades dadas - sino que ya no pertenecen a ninguna comunidad en absoluto [la traducción es nuestra]. ${ }^{13}$

Las perplejidades involucradas en la pérdida de los derechos humanos coincide con el hecho de que la persona deviene en un ser humano en general - sin profesión, sin ciudadanía, sin opinión, sin nada que lo identifique consigo mismo-, para quien su propia individualidad, absolutamente única, privada de expresión y acción al interior de un mundo común, carece de todo significado. El riesgo que esto involucra es que incrementa la amenaza de nuestra vida política y, en esta misma dirección, la emergencia de Gobiernos totalitarios surgidos al interior de nuestra civilización. En un mundo global, como explica Arendt, erigido sobre la base de una "civilización" interrelacionada universalmente, estamos expuestos constantemente a los barbarismos creados desde las propias estructuras del Estado-nación, que arrojan a millones de personas a la salvaje condición de convertirlas en "seres humanos en general". ${ }^{14}$

De un modo provocativo, en el capítulo nueve de Los origenes del totalitarismo, dedicado a "La declinación del Estado nación y el fin de los derechos humanos del hombre", Arendt escribe la frase: "El derecho a tener derechos". ${ }^{15}$ Con extraordinaria elocuencia, Frank Michelman asegura que esta frase presupone la existencia de personas que no cuentan con ninguno de esos derechos. ${ }^{16} \mathrm{El}$ reclamo de Arendt significó su objeción en contra de que nadie era reconocido en la posición de "no tener derechos", cuando en realidad la mayoría de la población en el mundo estaba siendo objeto de desnaturalizaciones masivas que las dejaban sin derecho a tener derechos.

Esta noción surge de las nuevas condiciones del Estado moderno y es equivalente al reclamo moral de un refugiado, una persona "sin Estado" o un desplazado, a la ciudadanía, o por lo menos a una personalidad jurídica dentro de los límites sociales de alguna ley de dispensación estatal. ${ }^{17}$ Dadas las circunstancias presentes, en algún momento una persona podría encontrarse

\footnotetext{
${ }^{13}$ Arendt, Hannah, The Origins..., op. cit., pp. 293-295.

${ }^{14}$ Ibidem, p. 302.

${ }^{15}$ Ibidem, pp. 296, 298.

${ }^{16}$ Michelman, Frank, "Parsing 'Right to Have Rights”', Constellations, vol. 3, núm. 2, 1996, pp. 200-208.

${ }^{17} \mathrm{Ibidem}$, p. 203.
} 
en esta condición, expulsada de todo derecho. La exigencia contenida en el "derecho a tener derechos", se refiere a un reclamo en nombre de aquellos cuya situación actual no satisface los requisitos de tener derechos en el enmarcamiento del sistema de Estados-nación, como sucede en la actualidad con millones de migrantes sin papeles, refugiados, asilados o desplazados.

La dureza y el escepticismo con los que Arendt estructura su diagnóstico sobre los derechos humanos corresponden a una pensadora judía-alemana que sobrevivió a la desnacionalización y persecución de los judíos en la Alemania nazi. Fue observadora y testigo participante de la diáspora mundial de la comunidad judía y conocedora coexistente de otras minorías (alemanes en Rusia; eslovacos en Checoslovaquia; musulmanes en Yugoslavia; gitanos y muchos más) en la Europa de mediados del siglo pasado, cuyo rasgo identitario fue la sistemática desnaturalización, persecución y asesinato. Esta práctica tuvo lugar dentro de las estructuras de las leyes nacionales e internacionales en el contexto de los tiempos modernos. Pero, ¿en qué radica la imposibilidad de llevar a cabo la realización de los derechos humanos, tanto en las declaraciones tradicionales formuladas a finales del siglo XVIII como en la de 1948?

Ciertamente, como afirma Agamben, responder a esta interrogante implica abandonar la manera tradicional de pensar el concepto de "hombre, ciudadano y sus derechos". ${ }^{18}$ Incluso, conlleva desdeñar la argumentación universal y reconstruir un principio universal de justicia. ${ }^{19}$ Las aporías de Arendt indagan precisamente el vínculo "fracturado" entre los derechos del hombre y los derechos humanos, sintetizados en la frase: "el derecho a tener derechos", donde la premisa no depende de la ley natural moderna, anclada al pensamiento liberal, sino que pone en duda los presupuestos básicos de la tradición. ${ }^{20} \mathrm{Al}$ respecto, Arendt escribe:

Tomamos conciencia de la existencia de un derecho a tener derechos (y eso significa vivir en un marco en el que uno es juzgado por sus acciones y opiniones) y un derecho a pertenecer a algún tipo de comunidad organizada, sólo cuando aparecieron millones de personas que habían perdido y no podían recuperar sus derechos debido a la nueva situación política global [...] El derecho que corresponde a esta pérdida y que nunca fue mencionado entre los derechos humanos porque no pudo expresarse en las categorías del siglo XVIII, ya que

\footnotetext{
${ }^{18}$ Agamben, Giorgio, State of Exception, Chicago - Londres, University of Chicago Press, 2000, p. 16.

${ }^{19}$ Cohen, Joshua, "Pocedure and Substance in Deliberative Democracy" en Seyla Benhabib (ed.), Democracy and Difference: Contesting the Boundaries of Political, Princeton, Princeton University Press, 1997, p. 183.

${ }^{20}$ Menke, Christoph, Kaiser, Birgit y Thiele, Kathrin, "“Aporias of Human Rights' and the 'One Human Rights': Regarding the Coherence of Hannah Arendt's Argument”, Social Research, vol. 74, núm. 3, 2007, p. 741 .
} 
éstas suponen que los derechos tienen su origen en la "naturaleza" del hombre [...] es el derecho a tener derechos o el derecho de todo individuo a pertenecer a la humanidad, mismo que debería estar garantizado por la humanidad misma. Sin embargo, no es de ningún modo seguro que esto sea posible [la traducción es nuestra]. ${ }^{21}$

En este sentido, como afirma Menke, la primera objeción que subraya Arendt contra la Declaración Universal de los Derechos Humanos de 1948, compete a la visible "pérdida de realidad", derivada de la imposibilidad de llevar a cabo un deber al que no puede corresponder por su incapacidad de acción. ${ }^{22}$ Para retomar esta pérdida de realidad, es preciso analizar la noción del "derecho a tener derechos". Si se observa con atención, esta afirmación evoca dos ámbitos interconectados en el pensamiento de Arendt: (derecho)-a-(tener derechos). El principio de la frase, como señala Benhabib, remite a un imperativo moral a la membrecía y, por lo tanto, de una forma de relación compatible con la membrecía.

Esta primera estructura del derecho, dirigida a la identidad de los otros, a quienes se reclama el reconocimiento como una persona derechohabiente, queda abierta e indeterminada; no depende de la precondición de ser ciudadano o no, sino del derecho al reconocimiento por el simple hecho de ser un ser humano..$^{23}$ Tal reconocimiento en Arendt es, en primer lugar, el derecho a la membrecía, a la pertenencia de alguna comunidad humana organizada. De este modo, la humanidad misma se convierte en la destinataria de este reconocimiento; "sin embargo, no es de ningún modo seguro que esto sea posible".

Así, la condición de persona es contingente a su reconocimiento en la membrecía, lo que permite introducir la noción de la segunda frase de la estructura discursiva tener derechos, cuya acción resulta del previo derecho a la membrecía, lo cual significa el derecho (y sus respectivos deberes) a vivir como miembro de una comunidad humana organizada en la que las personas son juzgadas por sus acciones y opiniones. ${ }^{24}$ Esta doble adscripción del "derecho a tener derechos" rompe las formas a priori de la pertenencia a una comunidad humana organizada, basada en la egología trascendental kantiana. En esta última se reúnen, merced a una prodigiosa decisión, los derechos humanos a la ciudadanía, dejando sin protección a individuos y pueblos frente a las arbitrariedades de la soberanía del Estado. Por un lado, postula una comunidad jurídico-civil de socios que estén en relación con el deber de

\footnotetext{
${ }^{21}$ Arendt, Hannah, The Origins..., op. cit., pp. 296-298.

${ }^{22}$ Menke, Christoph, Kaiser, Birgit y Thiele, Kathrin, op. cit., p. 741.

${ }^{23}$ Benhabib, Seyla, The Rights of Others. Aliens, Residents and Citizens, Cambridge, Cambridge University Press, 2004, p. 56.

${ }^{24}$ Ibidem, p. 57.
} 
responsabilidad recíproca. Y, por otro, el deber de reconocerse mutuamente como miembros, como individuos protegidos por las autoridades políticolegales, quienes deben ser tratados como personas habilitadas para disfrutar de derechos. ${ }^{25}$

Desde el punto de vista de Arendt, la ficticia y obtusa simbiosis del derecho a la membrecía y el derecho a vivir como un miembro de una comunidad humana organizada caracterizan las declaraciones tradicionales de derechos humanos. Esta particularidad se reprodujo en la Declaración Universal de los Derechos Humanos, promulgada por la Asamblea General de Naciones Unidas en diciembre de 1948, principio que impide su realización. Desde un inicio, dice Arendt, la Declaración de los Derechos del Hombre y del Ciudadano del siglo XVIII presentó a un ser humano "abstracto" que no existía en ningún sitio. ${ }^{26}$

De manera inexplicable, la cuestión de los derechos humanos rápidamente quedó adherida a la emancipación nacional, lo que muy pronto derivó en la idea de que la soberanía de un pueblo emancipado era la única que parecía asegurar los derechos "inalienables", limitando su acceso únicamente a quienes pertenecían a la nueva comunidad organizada. Desde la Revolución francesa, el ser humano fue concebido a través de la imagen de una familia de naciones. No obstante, en el trayecto se evidenció que el pueblo, y no el individuo, constituía la imagen de hombre. ${ }^{27}$

El principio de que todos los derechos dependen de la ley y toda legislación política está necesariamente atada a una forma específica de "localidad", de acuerdo con la afirmación realista de Edmund Burke ${ }^{28}$ revela a Arendt las lindes de los derechos que ejercemos al circunscribirse a la nación, donde ninguna ley natural o divina, ni ningún concepto de humanidad, son requeridos como fuente de ley. ${ }^{29}$ Por el contrario, remitir los derechos del hombre - al hecho de ser hombre - obliga a todo individuo o comunidad humana a respetarlos siempre. Si los supeditamos al hecho de ser ciudadano, solamente serán respetados cuando la nación que da la ciudadanía tenga la voluntad de hacerlo. Si el Estado-nación es la única autoridad jurídica que reconoce y realiza los derechos humanos, este discurso pierde su significado para quienes viven procesos de expatriación, emigración forzada o cualquier otro tipo de dimisión de pertenencia a una entidad política.

La privación primordial de los derechos humanos se manifiesta en la pérdida de un lugar en el mundo, donde las opiniones y la acción colectiva toman forma. Esta privación, como ninguna otra, despoja del derecho a la acción

\footnotetext{
${ }^{25}$ Ibidem, pp. 57-58.

${ }^{26}$ Arendt, Hannah, "The Rights of Man...", op. cit., p. 31.

${ }^{27}$ Arendt, Hannah, The Origins..., op. cit., p. 291.

${ }^{28}$ Burke, Edmund, Reflections on the Revolution in France, Indianapolis - Cambridge, Hackett, 1987, p. 9.

${ }^{29}$ Arendt, Hannah, "The Rights of Man...", op. cit.
} 
y sin ésta ningún derecho es realizable. ${ }^{30}$ Este punto constituye un elemento crucial para comprender las implicaciones del "derecho a tener derechos" en términos del derecho moral a la membrecía y el tener derechos al interior de una comunidad humana organizada. La importancia de esta dimensión permanecerá ausente en las declaraciones de derechos humanos existentes. La ligereza, al hablar de los derechos humanos, conduce a la confusión y a la "pérdida de realidad" expresada en el contenido de estos instrumentos.

Como apunta Reyes Mate, asegurar que "existen" unos derechos humanos supone un doble despojo: otorgan a un hombre abstracto, que no existe, los atributos que no tiene el hombre concreto y se niega a la cruda realidad (de hombres sin derechos) capacidad de significación teórica. Finalmente, se construye una doctrina de derechos sobre el hombre que no tiene en cuenta al hombre real, sino a uno abstracto que se ha inventado la filosofia, que tiene el inconveniente de no existir. ${ }^{31}$

La redefinición del concepto de derechos humanos requiere de una respuesta que conjugue los derechos de membrecía con el derecho a ser miembro a la luz de las experiencias de las circunstancias presentes. La obra de Arendt postula un ejercicio de la libertad de acción política que podría ser leído en clave para dar inicio al "derecho a tener derechos" y, de este modo, pensar los derechos humanos en otro registro.

\section{LA LIBERTAD DE ACCIÓN POLÍTICA Y LA REALIZACIÓN DE LOS DERECHOS HUMANOS}

En su crítica a los derechos humanos, dentro del contexto de la Segunda Guerra Mundial, Arendt se pregunta por qué el concepto de derechos naturales e inalienables falló a la humanidad en el momento que más se necesitaban, a pesar de que éstos habían sido pronunciados un siglo y medio antes en Francia. A esto, responde que cuando el individuo carece de pertenencia a una comunidad política, sus derechos no son tan sagrados como el concepto de derechos individuales sugería. ${ }^{32}$ La facultad política simplemente es incapaz de realizarse en los desposeídos, si éstos no son reconocidos como miembros iguales de la humanidad.

En Hegel también aparece la tensión entre la ley de lo singular y la de lo universal, como característica intrínseca de la unidad ${ }^{33}$ (a la cual apela en un contiguo despliegue dialéctico), con el propósito de lograr un acercamiento

\footnotetext{
${ }^{30}$ Arendt, Hannah, The Origins..., op. cit., p. 296.

${ }^{31}$ Mate, Reyes, "Hannah Arendt y los derechos humanos", Arbor, ciencia, pensamiento y cultura, vol. 186, núm. 742, marzo-abril, 2010, p. 243.

${ }^{32}$ Arendt, Hannah, The Origins..., op. cit., p. 293.

${ }^{33}$ Hegel, Georg Wilhelm Friedrich, Fenomenología del espiritu, México, Fondo de Cultura Económica, 1985, p. 473 .
} 
distinto. De dicho acercamiento emerge la idea de que la unidad está atravesada, no sólo por la resolución de los contrarios, sino por la perplejidad que los contiene. Arendt identifica con claridad esta tensión entre las dos dimensiones propuestas en el "derecho a tener derechos", de la cual emerge la concepción de libertad; pero también se sabe que esta última debe prefigurar un movimiento que conduzca a la acción de la vida política, si de lo que se trata es de romper la aporía de los derechos humanos. Considera que la realidad moderna fue, en muchos sentidos, resultado de la dualidad práctica y teórica de la libertad postulada por la filosofía política occidental.

Para demostrarlo, gira su análisis a la filosofía presocrática, donde la libertad era considerada como un concepto exclusivamente político, la quintaesencia de la ciudad-estado y la ciudadanía, en contraste con la tradición filosófica del pensamiento político clásico - iniciada con Parménides y Platón - que la funda explícitamente en oposición a la polis y su ciudadanía. El modo de vida elegido por estos últimos fue entendido en oposición al modo de vida político. Sólo cuando los primeros cristianos, particularmente Pablo (Saulo de Tarso), descubrieron un tipo de libertad desvinculado de la política, el concepto entró a la historia de la filosofía. Libre albedrío y libertad se convirtieron en sinónimos y la libertad fue experimentada en términos de un ejercicio de completa soledad. ${ }^{34}$

El concepto de libertad entró en el vocabulario de la filosofía hasta la Antigüedad tardía; cuando lo hizo, fue usado por pensadores tales como Epictetus y Agustín de Hipona para formular la condición en la que un individuo conservaría su libertad dentro de sí mismo, a pesar de ser privado de ella en el mundo físico. Arendt acentúa el hecho histórico de que la aparición del problema de la libertad en la filosofia de Agustín fue precedido del intento consciente de divorciar la noción de libertad de la política, y así llegar a la formulación de que uno puede ser esclavo en el mundo y aún conservar su libertad. ${ }^{35}$

La tradición cristiana jugó un papel decisivo en el problema de la libertad. Convirtió en sinónimos la libertad y el libre albedrío, al mismo tiempo que arrojó la experiencia de la libertad al terreno de la completa soledad. Todavía hoy, cuando pensamos en la libertad, inmediatamente se establece la equivalencia entre estas dos nociones, la cual fue una facultad virtualmente desconocida por los presocráticos. Por su parte, el concepto de libertad de Epictetus, en el que clama que quien comienza con la afirmación de que es libre es el que lleva a cabo lo que desea, no es más que el reverso de la noción de la libertad de la antigua noción política y el trasfondo político sobre el que la filosofía popular sustentó la disminución evidente de la libertad a finales del Imperio romano, manifiesta en las nociones de poder y dominación. ${ }^{36}$

\footnotetext{
${ }^{34}$ Arendt, Hannah, Between Past and Future, Nueva York, Penguin Classics, 2006, p. 156.

${ }^{35}$ Ibidem, p. 146.

${ }^{36}$ Ibidem.
} 
Los presocráticos fueron inexpertos en los fenómenos de la soledad. Sabían muy bien que el hombre solitario ya no es uno, sino dos-en-uno, ya que la relación entre el yo y yo mismo comienza en el instante en el que $m i$ relación con mis semejantes ha sido interrumpida por alguna razón. El dualismo de la filosofía clásica (desde Platón) ha insistido en la dicotomía entre el alma y el cuerpo, al asignar la moción de la facultad humana al alma. Esta dualidad, alojada dentro de la capacidad del sí mismo, es conocida como una característica del pensamiento, el diálogo que uno sostiene con uno mismo.

Sin embargo, dirá Arendt, el dos-en-uno de la soledad que genera el proceso del pensamiento tiene un efecto exactamente contrario sobre la voluntad: la paraliza y la bloquea; dispuesta en soledad, se encuentra siempre y al mismo tiempo entre querer (velle) y no querer (nolle). El efecto paralizante de la voluntad que tiene su efecto sobre el sí mismo configura la verdadera esencia del mandar y ser obedecido. Platón insistía en que solamente aquellos que supieran establecer las reglas para ellos mismos tenían derecho a instaurar reglas para los otros, quienes serían libres desde la obligación de la obediencia. ${ }^{37}$

En el renacimiento del pensamiento político, el cual vino acompañado de la Edad moderna, Arendt distingue entre aquellos pensadores, quienes sustentan el título de "padres de la ciencia política" - Maquiavelo y Hobbes, como sus mayores representantes - y aquellos que remontaron su preocupación al pensamiento político presocrático, no por ninguna predilección por el pasado, sino porque la separación entre Iglesia y Estado había producido un ámbito secular independiente, desconocido en el entorno político desde la caída del Imperio romano.

El representante de este secularismo es Montesquieu. Aunque indiferente a los problemas estrictamente filosóficos, tenía una profunda preocupación por la inadecuada concepción de la libertad para los propósitos políticos desarrollada por los filósofos cristianos. Con el fin de zanjar esta cuestión, propuso una distinción entre libertad filosófica y libertad política. Desde su perspectiva, la filosofía no demanda más libertad que el ejercicio de la voluntad, separadamente de las circunstancias y la consecución de los objetivos que la voluntad se haya fijado. Por el contrario, la libertad política consiste en la capacidad de hacer lo que la voluntad dispone.

Tanto para Montesquieu como para los presocráticos, estaba claro que un agente deja de ser libre en el instante en que pierde su capacidad de hacer; por lo tanto, es irrelevante si esa falla es causada por circunstancias internas o externas. ${ }^{38}$ Los antiguos griegos convirtieron la preocupación de la voluntad en una facultad separada de las otras capacidades del hombre. Históricamente, el hombre descubrió por primera vez la voluntad cuando

\footnotetext{
${ }^{37}$ Platón, La República, Madrid, Alianza, 2006, libros 5 y 6, pp. 349-403.

${ }^{38}$ Arendt, Hannah, Between..., op. cit., p. 159.
} 
experimentó su impotencia, no su poder. Esto tiene importancia para darse cuenta que los tempranos testimonios sobre la voluntad no fueron derrotados por la abrumadora fuerza de la naturaleza o de las circunstancias y que su aparición no planteó el conflicto del uno contra otros ni la lucha entre el cuerpo y la mente. Diferente a este planteamiento es la relación del pensamiento y el cuerpo en Agustín, la cual tiene su fuente en el enorme poder inherente a la voluntad, el pensamiento manda al cuerpo y éste obedece inmediatamente. El cuerpo representa, en este contexto, el mundo exterior y de ninguna manera es considerado en términos del sí mismo.

Epictetus estima que en el dominio interior, dentro del sí mismo, el hombre deviene en maestro absoluto y, precisamente, el conflicto entre el hombre y él mismo es derrotado por la voluntad. La fuerza de voluntad cristiana descubrió esta vía como una forma de autoliberación, cuyo principio adoptó en seguida. De esta forma, mi voluntad (I-will) paraliza instantáneamente mi capacidad de hacer $(I$-can). En el mismo momento en que el hombre desea la libertad, pierde su capacidad para ser libre. Arendt permanece atenta a las consecuencias fatales que este proceso tiene para la teoría política, toda vez que en la ecuación de la libertad con la capacidad humana de la voluntad es posible encontrar la causa por la que hoy, de manera automática, establecemos la equivalencia entre el poder y la opresión. ${ }^{39}$

Arendt afirmó que los filósofos mostraron interés en el problema de la libertad cuando descubrieron que podían desvincularla de la política, de experimentarla fuera del ámbito de la actuación y asociación con los demás y limitada a la relación de la voluntad con uno mismo, es decir, asumida como libre albedrío. Esto convirtió la cuestión de la libertad en un problema filosófico de primer orden y, como tal, en un problema referido al ámbito político. El cambio filosófico de la acción a la fuerza de voluntad y la libertad referida a un modo de ser manifiesto en la acción del libre albedrío transformó el ideal de libertad en uno de voluntad, independiente de los demás, que más tarde adoptará la forma de soberanía. Este principio prevaleció hasta el siglo XVIII. Thomas Paine sostendrá que "ser libre es suficiente [para el hombre] que lo desea", palabras que Lafayette aplicará al Estado-nación: "Para que una nación sea libre, es suficiente que quiera serlo".

Estas ideas tuvieron resonancia en la filosofía política de Jean-Jacques Rousseau, el representante más reconocido de la teoría de la soberanía derivada directamente de la voluntad. ${ }^{40}$ En su teoría no escatima las consecuencias del individualismo extremo que el principio de voluntad, independientemente de los demás, supone. Incluso argumenta - en contra de Montesquieu- que el poder soberano debe ser indivisible porque una división del poder sería

\footnotetext{
${ }^{39}$ Ibidem, pp. 160-161.

${ }^{40}$ Rousseau, Jean-Jacques, El contrato social o Principios del derecho politico, Madrid, Tecnos, 2002.
} 
impensable. Adicionalmente, precisa que en un Estado ideal los ciudadanos no tendrían comunicación unos con otros y que con el propósito de evitar confrontaciones, cada ciudadano debía pensar solo sus propios pensamientos. Arendt refutará estos planteamientos. Un Estado en el que no existe comunicación entre los ciudadanos y donde cada uno piensa solo, en sus propios pensamientos, es por definición una tiranía. Por ello, la identificación política entre libertad y soberanía es la más perniciosa y peligrosa consecuencia de la ecuación filosófica de libertad y libre albedrío, debido a que conduce a una negación de la libertad humana. ${ }^{41}$

Revisitar las tradiciones presocráticas y su política implica para Arendt recuperar la experiencia de la libertad en el proceso de actuar (juntos). Cuando afirma que el concepto de libertad no jugó un papel importante en la filosofia clásica griega, apunta específicamente al "borramiento" del origen exclusivamente político. Para nuestra autora, la libertad supone el comienzo de la realización de algo, el inicio que anima e inspira todas las actividades humanas, la acción como principio de la vida política. ${ }^{42}$ La libertad no refiere un modo de ser, una virtud o virtuosismo, sino un don supremo que el hombre recibió entre todas las criaturas terrenales, cuya manifestación se expresa en todas las actividades que experimenta: "La libertad se realiza sólo cuando su acción crea el espacio de aparición del hombre". ${ }^{43}$ Las tradiciones cristianas y antifilosófico políticas, reitera Arendt, despojaron a la libertad del atributo de actuar (juntos). A su pesar, esta concepción fue la que trasminó en el pensamiento de los filósofos modernos.

Hobbes, Spinoza e incluso Kant comprendieron la libertad fuera de la política. ${ }^{44}$ Este deslizamiento teórico llevó a la humanidad a la justificación de que los hombres tienen la capacidad de vivir legal y políticamente juntos, únicamente cuando algunos tienen el derecho de mandar y otros son forzados a obedecer. ${ }^{45}$ Para Arendt, la experiencia moderna del totalitarismo, los apátridas y el genocidio es resultado de este deslizamiento que condujo a la pérdida de la acción como principio de la vida política, traslación que el concepto de derechos humanos — naturales e inalienables - fue incapaz de identificar y revertir. Precisamente en este intersticio vislumbra la libertad de acción política como una vía para conectar las dos dimensiones del (derecho)a-(tener derechos) poniendo en cuestión las formas tradicionales del ejercicio de la justicia en su precaria ejecución.

La relevancia de Arendt al postular la libertad como acción política radica en desplazar el debate acerca de si los derechos humanos tienen validez uni-

\footnotetext{
${ }^{41}$ Arendt, Hannah, Between Past..., op. cit., pp. 162-163.

${ }^{42}$ Arendt, Hannah, La condición humana, Barcelona, Paidós, 2005.

${ }^{43}$ Arendt, Hannah, Between Past..., op. cit., p. 164.

${ }^{44}$ Hansen, Phillip, Hannah Arendt: Politics, History and Citizenship, Standford, Stanford University Press, 1993.

${ }^{45}$ Arendt, Hannah, Between Past..., op. cit., p. 222.
} 
versal hacia la creación de un espacio público, local y global, donde el ser humano actúe, hable y opine para demandar la realización de los mismos. Construye un puente, entre los principios de la Declaración Universal de los Derechos Humanos y su materialización, poniendo en acto la promesa de algo diferente por venir. Mediante la acción, crea la relación entre política y ley, cuya expresión se manifiesta en el momento en que los actores demandan el reconocimiento de sus derechos humanos. Esta interacción dinámica entre política y ley, como señala Robert Post, visibiliza el vínculo entre la demanda de derechos y las formas tradicionales del ejercicio de la justicia:

La política y la ley constituyen dos formas distintas de gestión para resolver el acuerdo o desacuerdo de los hechos sociales inevitables. Como prácticas sociales, la política y la ley son independientes e interdependientes. Son independientes en el sentido de que son incompatibles. Someter una controversia política a una resolución legal implica sacarla del dominio político, del mismo modo que someter una controversia legal a una resolución política implica debilitar la ley. Sin embargo, política y ley son interdependientes, en el sentido de que la ley requiere de la política para producir las normas compartidas que impone la ley, mientras que la política exige de la ley para estabilizar y consolidar los valores comunes de la política que se esfuerza por lograr [la traducción es nuestra]. ${ }^{46}$

La acción política en este registro coloca a las instituciones westfalianas frente al problema de la representación política y la injusticia en el sentido directo de voz pública y responsabilidad democrática, al apelar a normas cosmopolitas ${ }^{47}$ que rebasan la triada Estado-ciudadanía-derechos humanos. ${ }^{48}$ Asimismo, involucra formas de reconocimiento que no se limitan a la participación de

\footnotetext{
${ }^{46}$ Post, Robert, "Theorizing Disagreement: Reconceiving the Relationship Between Law and Politics", California Law Review, vol. 98, núm. 6, 2010, p. 1343.

${ }^{47}$ Los siguientes tratados y convenios constituyen tan sólo un reducido ejemplo de esta nueva configuración: el Convenio sobre la Eliminación de Todas las Formas de Discriminación Racial, el Convenio Internacional sobre Derechos Civiles y Políticos, el Convenio sobre la Eliminación de Todas las Formas de Discriminación contra las Mujeres, el Convenio Contra la Tortura y otros Tratos o Castigos Crueles, Inhumanos o Degradantes (Naciones Unidas). La articulación de la Unión Europea se hizo acompañar por la Carta de Derechos Humanos y Libertades Fundamentales en la que participan estados "no miembros de la Unión Europea”. Permite a los ciudadanos realizar demandas que son escuchadas por una Corte Europea de Derechos Humanos. Esta carta fue adoptada como recomendación y texto de referencia en el Consejo Europeo de Niza en diciembre de 2000 (Parlamento Europeo). En esta misma dirección, el continente americano estableció en 1948 el Sistema Interamericano para la Protección de Derechos Humanos (SIDH), con el propósito de proteger a los habitantes de América frente a la violación de sus derechos humanos por parte del Estado. Asimismo, se creó la Corte Interamericana de Derechos Humanos, cuya función es aplicar e interpretar la Convención Americana sobre Derechos humanos y otros tratados de derechos humanos a los que se somete el SIDH (Organización de los Estados Americanos).

${ }^{48}$ Fraser, Nancy, Escalas de justicia, Barcelona, Herder, 2008, pp. 257-258.
} 
quienes se hallan dentro del universo de los que "cuentan" en el ámbito de una comunidad política organizada, sino que es resultado del punto de intersección entre el enmarque moral y la participación democrática. Esto es, la discusión sobre la aplicación de la justicia se desenvuelve a través de un ejercicio normativo, en el que las instituciones jurídicas son atravesadas por narrativas y prescripciones sociales. ${ }^{49}$ En este sentido, Arendt no reduce el "aparecer" del ser humano en términos de un horizonte puramente fenomenológico, sino que lo extiende a una dimensión propiamente ontológica. No falta, como afirma Esposito, la vertiente escénica en la que los "sujetos de la política" llevan a cabo su aparición como actores en un escenario dispuesto por ellos mismos, donde el aparecer tiene el sentido de "venir a la luz" y, en esa experiencia, "existir".${ }^{50}$ La lucha por los derechos humanos reemprendida durante los años sesenta constituye un importante ejemplo para el planteamiento de reclamos y la búsqueda de la justicia en este sentido. ${ }^{51}$

Lo que sigue de esto es una nueva apreciación del papel de la libertad entendida como acción política, cuya práctica podría precipitar la realización de los derechos humanos en lo por venir. ${ }^{52}$ Lo que pone en juego no son únicamente cuestiones de primer orden de la justicia, sino también las "metapreguntas" acerca de cómo estos problemas deben ser enmarcados. Mediante su práctica estimula una política jusgenerativa y otorga un nuevo sentido a la ley, donde "el demos enfrenta la disyunción entre el contenido universalista de sus compromisos constitucionales y las paradojas del cierre democrático". ${ }^{53}$ Esto da lugar a nuevas formas de pertenencia desterritorializadas, al debilitar la línea que separa los derechos humanos de los derechos ciudadanos.

Si la precondición para ser juzgado por las acciones y opiniones exige rasgar desde afuera a través del derecho a pertenecer, y de esta manera reanudar el derecho a ser miembro, este movimiento tiene lugar cada vez que un con-

\footnotetext{
${ }^{49}$ Cover, Robert, "Foreword: Nomos and Narrative, The Supreme Court 1982 Term", Harvard Law Review, vol. 97, núm. 4, 1983-1984, p. 1.

${ }^{50}$ Esposito, Roberto, “¿Polis o comunitas?”, en Fina Birulés (comp.), Hannah Arendt. El orgullo de pensar, Barcelona, Gedisa, 2006, p. 119.

${ }^{51}$ Margaret L. Satterthwaite y Deena R Hurwitz proponen una selección de historias con resultados positivos sobre la defensa de los derechos humanos, donde política y ley establecen un diálogo del que surge un cambio en los modos del ejercicio tradicional de la justicia. Entre ellas destacan: Amnistía Internacional y sus esfuerzos por dar forma a la Convención de la onU contra la tortura; la Campaña de Acción Pro Tratamiento VIH/sida (TAC por sus cifras en inglés) en Sudáfrica; la lucha por la legalización de las identidades sexuales: el caso de Dudgeon y Toonen; el reconocimiento legal indígena sobre los derechos de la tierra: el caso de Awas Tingni en Nicaragua; la Ley de la República vs. la Ley de los hermanos, sobre la prohibición francesa de los símbolos religiosos en la escuela pública; el caso de Akayesu antes del Tribunal Criminal Internacional sobre el genocidio en Ruanda; las paradojas de la construcción del Estado y los derechos humanos, el caso de Kabul en Afganistán. Véase Hurwitz, Deena, R. y Stterthwaite, Margaret (eds.), Human Rights Advocacy Stories, Nueva York, Thomson Reuters Foundation Press, 2010.

${ }^{52}$ Parafraseando a Jacques Derrida, diremos que lo por venir no significa que hoy no tengamos justicia o democracia para hacer posibles los derechos humanos - pero que las tendremos a futuro-, sino que actuamos para precipitar su llegada.

${ }^{53}$ Benhabib, Seyla, The Rights of Others..., op. cit., p. 25.
} 
junto de personas abren espacios para denunciar y, en el trayecto, desafiar los imaginarios y mapas cognitivos tradicionales sobre los derechos humanos. Aunque en sus demandas no se esboza un sentido específico sobre cómo los derechos humanos tendrían que dar lugar al derecho de pertenencia a una comunidad política organizada, actúan impulsados por la convicción de que las condiciones actuales dañan la igualdad, la libertad y la justicia, y asumen que con su acción empujan hacia un mundo más justo y equitativo.

Con este acto comienzan a modificar las cosas, simplemente por el hecho de actuar juntos, en una acción performativa en la que inauguran un lugar para ser escuchados, más allá de los límites estatales. El imperativo moral de membrecía ${ }^{54}$ y, por lo tanto, la apelación a una relación compatible con la membrecía, demandados por la gente cuando exige a las autoridades que se hagan responsables de la "humanidad", resquebraja algo, pasa por la experiencia de que luchamos por lo que nunca hemos tenido, pero que siempre estará por venir, en el sentido de que nunca dejará de llegar y en cada acción plural comienza a suceder.

En esta experiencia, la condición de persona se vuelve contingente a su reconocimiento en la membrecía, introduciendo el derecho (y sus respectivos deberes) a vivir como miembro de una comunidad humana organizada en la que es juzgado por sus acciones y opiniones. Solamente si las personas son vistas y asumidas, no simplemente como sujetos de ley, sino como autoras de la propia ley, la contextualización e interpretación de los derechos humanos puede ser creíble, en términos de un proceso de opinión democrática. Tal contextualización logra legitimidad en la medida en que es resultado de la interacción entre instituciones legales y políticas dentro de espacios públicos libres. Cuando tales derechos son asumidos por la gente como propios, mediante el reclamo moral puesto en marcha a través de la acción colectiva, pierden su parroquialismo y, como tal, abren la posibilidad de su realización, basados en el "derecho moral a ser miembro" y "tener derechos dentro de una comunidad humana organizada".

La lectura que propone Arendt de la libertad entendida como acción política, re-significa la idea de los derechos humanos, postulada en las declaraciones de derechos humanos, y potencia la doble adscripción del "derecho a tener derechos". Agrieta las formas a priori de pertenencia y vislumbra una comunidad jurídico-civil de co-socios en relación con el deber de responsabilidad recíproca - protegidos por las autoridades político-legales-, quienes deben ser tratados como personas habilitadas para disfrutar de todos sus derechos. Sin embargo, es preciso señalar que si bien este planteamiento logra horadar muchas de las perplejidades contenidas en las Declaraciones,

\footnotetext{
${ }^{54}$ Griffin, James, "Human Rights: Questions of Aim and Approach”, Ethics, vol. 120, núm. 4, 2010, pp. 741-760.
} 
debemos estar muy atentos a los resultados de la acción política que hoy irrumpe en el ámbito local y global para demandar la realización de los derechos humanos, toda vez que la acción no se termina si no cesa ella misma. Una acción sin obra, como afirma Nancy, podría devenir en una "comunidad inoperante". ${ }^{55}$

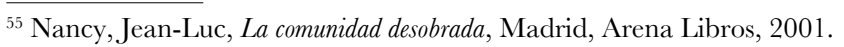

